\title{
Error Treatment Sequence in Classrooms with Native English and Non-Native English Teachers
}

\author{
Sen Zhang (Corresponding Author) \\ M.A. student, Department of Languages and Linguistics, Faculty of Liberal Arts \\ Prince of Songkla University, Hat Yai Campus, Songkhla, Thailand \\ E-mail: mutation_mo@hotmail.com \\ Monta Chatupote \\ Assoc. Prof. Dr., Department of Languages and Linguistics, Faculty of Liberal Arts \\ Prince of Songkla University, Hat Yai Campus, Songkhla, Thailand \\ E-mail: monta.ch@psu.ac.th
}

Received: March 26, 2014 Accepted: April 9, 2014 Published: April 9, 2014

doi:10.5296/jsel.v2i1.5445 URL: http://dx.doi.org/10.5296/jsel.v2i1.5445

\begin{abstract}
This research aimed to study the error treatment sequences, namely, learner error and teacher feedback in 4 classrooms taught by 2 native English speaking and 2 non-native English speaking teachers respectively. 12.3 hours of classroom interactions were analyzed using the correction analytic model comprising teacher feedback, student uptake and student repair. Results showed that error treatment sequences including recast tended to lead to high rate of students' no response in both Native and Non-Native teachers' classes; while those consisting of elicitation, clarification and repetition, seemed to be more effective as could be seen in high rate of students' self-repairs in both types of classrooms; and the error treatment sequence linked by explicit correction generated more repairs in Non-Native teachers' class. All these results may suggest that both Native and Non-Native teachers should avoid producing error treatment sequences including recast and try to initiate the sequences containing elicitation, clarification or repetition in order to trigger student repairs effectively.
\end{abstract}

Keywords: Error treatment sequence, Corrective feedback, Different teacher types 


\section{Introduction}

In 1978, Hendrickson summarized five framing questions concerning the matter of error treatment process in the classroom: why the mistakes need to be corrected, when to correct them; what to be corrected; how to correct; who do the correction (Hendrickson, 1978). Within these puzzles, the past few decades witnessed a number of discussions on the mistake correction issues in classroom process, which still seemed hardly to resolve any of these five framing questions. However, previous researchers used to pay close attention to corrective feedback or interactive feedback, which, although didn't answer the five framing questions, were always crucial and highly connected with learner errors in classroom, and even to some extent demonstrated how competent speakers corrected learners' errors and what kind of errors they tended to correct.

Corrective feedback or interactive feedback, as teachers' comments, responses or reformulation of learners' incorrect or inappropriate utterances, plays a scaffolding role in error treatment procedure happened in classrooms, which was supported by both Output Hypothesis (Swain, 1985) and Interaction Hypothesis (Long, 1996). Output Hypothesis (Swain, 1985) states that comprehensible input might not be enough to achieve learners' language acknowledgement; modified output is also needed and necessary for completing the whole process of language mastery. Corrective feedback is just one typical kind of means that may trigger modified output from students. Meanwhile, Interaction Hypothesis (Long, 1996) claims that interactional modification can make input comprehensible for learners, which will finally facilitate learner acquisition (Long, 1996). Thus, corrective feedback and learner uptake, which stimulate the interaction between learners and teachers, can benefit language learning process (Long, 1996).

Numerous researchers, deriving from these statements, studied the effectiveness and functions of feedback in classroom interactions and made thriving and prosperous development on feedback functions in students' language learning process. Of particular relevance to the present study are the consecutive studies conducted by Roy Lyster (Lyster \& Ranta, 1997; Lyster, 2001; Panova \& Lyster, 2002). These studies stemmed from the foundation of Chaudron (1977, 1986, \& 1988), which developed a model of the mistake correction process including teacher corrections and students reactions, and Doughty (1994a), which defined teacher turns as feedback types, such as clarification request and recast (Doughty, 1994a). Later, Lyster and Ranta (1997) worked out a model of error correction sequence, namely student mistakes, teacher feedback and student responses, which constituted the main unit of analysis for this current research.

Using this error treatment sequence analysis, generally, previous studies have made some development on basic characteristics about feedback or error treatment. Lyster and Ranta (1997) compared teacher feedback with students' errors and uptake, and studied the effectiveness of types of feedback. Lyster (2001) further investigated teacher feedback and the relationship among student errors, student repairs and feedback types. Panova and Lyster (2002), using the error treatment model from previous study, corroborated the applicability of this model in a new classroom environment and compared the results with the previous 
studies.

Inspired by Lyster and Ranta (1997), Suzuki (2004) compared teacher feedback and student responses in a typical U.S. ESL context with the previous study. The results showed both similarities and some differences to those in the previous study, and possible explanations were that these diversities may account for different classroom context, learners' ages and their motivation in attending the class, teacher experience and the language used (Suzuki, 2004).

Li (2010) compared 33 primary studies and concluded that the effect of corrective feedback could be maintained over time, implicit feedback can be easily preserved and foreign language environment can facilitate the experiments or researches more than other classroom contexts. However, despite the achievements stated above, Li (2010) also suggested that future researchers would be better concentrate on exploring the factors influencing feedback effectiveness. Thus, more variables, such as learner abilities, cultural differences or even interlocutor types, are needed to be investigated (Li, 2010).

Despite the suggestion, there have been merely some researches concentrating on the effects of diverse learning environments, such as students, either high ability or low ability, learning with native-speaker or non-native-speaker teachers, factors which are inherent to general learning situation. Due to the fact that teacher types are common factors influencing the teaching process, studies on these will certainly contribute to the body of knowledge about the effects they have on learner outcomes and give more insights into pedagogical use. Thus, this present study focused on comparing the similarities and differences of error treatment sequence happening in classrooms with native and non-native English speaker teachers, discovering the relationship between teacher types and teacher feedback, learner uptakes, and finally giving some suggestions and implications for feedback providing in current teaching procedures.

\section{Literature Review}

\subsection{Basic Concept}

\subsubsection{Error Treatment Sequence}

Making errors is an essential part of the process in SLA. Hendrickson's (1978) five framing questions and the following studies on these questions already demonstrated the importance of the error correction process. Later, both Output Hypothesis (Swain, 1985) and Interaction Hypothesis (Long, 1996) highlighted the necessity of studying the error treatment process in classroom.

Chaudron (1977, 1986, \& 1988) developed an error correction process model which compared students' errors, response and teachers' correction and formed the basic error treatment sequence. Doughy (1994a) later coded learner turns and teacher feedback in the classroom sequence, such as clarification request and recast, which brought the main content to the error treatment sequence. Deriving from these studies, Lyster and Ranta (1997) devised a more detailed and ordered error treatment model, which included student mistakes, teacher 
feedback and student responses. Using this sequence, Lyster (Lyster \& Ranta, 1997; Lyster, 2001; Panova \& Lyster, 2002) conducted consecutive studies which exhibited details of error correction process in 4 classrooms, the relationships among teacher feedback and learner errors and uptakes.

Since this current study focused on comparing error correction process happening in classrooms with different types of English teachers, some developments and changes, such as teacher types with teacher feedback, were made to adapt this error treatment sequence in the present situation.

\subsubsection{Teacher Feedback}

In teaching procedure, feedback refers to the comments or information, given by either teachers or other learners, to students' incorrect utterances (Richards, John, \& Heidi, 2000). However, as the teacher's response to students' errors, feedback has been defined differently based on varied disciplinary orientations (Lyster \& Ranta, 1997) in the past few decades. This current study focuses on corrective feedback used by second language lecturers.

Definitions of corrective feedback also differ in diverse studies. Within the interaction approach, corrective feedback arguably directs learners to focus on second language form (Long, 1996). While, Adams, Nuevo and Egi (2011) stated that teacher feedback referred to the conversational partners' negative comments to students' discourses which were not similar to the target language. According to Chaudron (1977), corrective feedback refers to any teachers' reactions that urge for or convert to students' improvement of the error utterance. Li (2010) stated that corrective feedback is the responses to learners' L2 utterance (usually the students' utterance with errors). Overall, corrective feedback is teachers' responses or reactions to learners' incorrect or unsuitable discourses, which may offer the corrections or slight indications to encourage learners to make some improvements of their errors or inappropriate utterances.

\subsubsection{Learner Uptake}

Usually, when studying teacher feedback in classroom, learner uptake which as the following sequence or the indication of feedback, was also used to compare teacher feedback and student responses, and to make the whole error treatment sequence integrated. Previously, uptake was defined as something that learners believe to have acquired from a specific course (Slimani, 1992). While, later Lyster and Ranta (1997) gave it a different notion - learners' discourses come after teachers' correction strategies instantly and form the response to teacher's intention of reminding the student of the inappropriate address. Yoshida (2010) defined learner uptake as learner response, which shows the student's state of understanding to teacher's comments or information.

To keep the consistency of teacher feedback and learner uptake, learner uptake in Lyster and Ranta's (1997) study were also applied in this current research, but with some adjustment of both teacher feedback and learner uptake due to the different classroom environment and students' characters. 


\subsection{Review of Related Researches}

The study, carried out by Lyster and Ranta (1997), initiated an analytical model of teacher-student utterance including six types of feedback and two types of uptake, and examined this sequence in four French immersion classrooms at the elementary level, during which the researchers analyzed and discussed the frequency and relationship of types of feedback and learner responses. Following this study, Panova and Lyster (2002) checked the applicability of this analytic model in an adult ESL classroom and found some similar results with Lyster and Ranta's (1997) study. Lyster (2001), based on the results from Lyster and Ranta (1997), further discussed the connections among teacher feedback, student errors and immediate student repairs, which made a more complete and comprehensible picture of error treatment sequence in classroom.

Consecutive studies by Lyster and Ranta (1997), Lyster (2001) and Panova and Lyster (2002) not only provided an analytic model, namely types of feedback and uptakes, for this current study, but also exhibited details of how to conduct the research about feedback types, how to compare the effectiveness or incidence of corrective feedback, and how to compare the relationship among teacher feedback, learner uptake and learner repair. Some aspects of design from these studies, such as collecting data from 4 classes, concentrating on communicative lectures and using the same error treatment sequence, were also applied in this current study.

Li (2010) conducted a study on teacher feedback through comparing 33 primary studies. The results exhibited that implicit feedback was better perceived by the learner than explicit feedback, feedbacks provided during foreign language contexts are more effective than second language context, and native-speaking teacher tended to provide more successful feedback types than the other teachers or computer. $\mathrm{He}$ (Li, 2010) also suggested that more variables, like learners' age, ability, classroom environment and even interlocutor types, were needed to be researched.

Since teacher types seem to have some effects on the corrective feedback in classroom, there are always some discussions about native and non-native teachers' teaching instructions. Some believes that native teachers have more advantages, since their language proficiency are higher. While, others would argue that non-native teachers may have the same cultural background with the students and could better understand their language difficulties (Clark \& Paran, 2007). Although native-speaker and non-native-speaker teachers may have some differences in language proficiency and teaching methods, Medgyes (1994) emphasizes that these do not mean that one type of teacher is more advanced than another. (Árva \& Medgyes, 2000). Therefore, to study teachers' teaching methods seems to be quite important since the effectiveness of feedback can be the indicator of teachers' teaching quality (Gibbons, 2003).

Of strong relevance and instruction to this current study was the study conducted by Noemi (2009), which made a comparison between native-speaker and non-native-speaker teachers' scaffolding strategies in young students' second language learning process (Noemi, 2009). By creating a new classification of teachers' scaffolding techniques, this study analyzed the relationship between teacher types and instructive methods, and found that native teachers 
preferred to elaborate their language to students, while non-native teachers liked to elicit students' responses (Noemi, 2009).

With the coming of The ASEAN Community, learning English becomes an urgent necessity for most Asian learners, which may further their career during this flourishing age. However, there are quite a lot of problems and difficulties in Asian learners' language acquisition process. Thus, studies on teacher-students sequence in classrooms are needed to understand the difficulties and provide some instructions for the practical learning process. The present study attempts to discover feedback used in both native English and non-native teacher classes, to explore the relationship between teacher types and feedback effectiveness, and tries to provide some insights of teachers' perceptions and students' preference of feedback. All these will certainly contribute to better understanding of classroom procedure which can lead to success in teaching and learning.

\section{Research Questions}

3.1 What are the overall error treatment sequences in all four classrooms?

3.2 What are the similarities and differences of error treatment sequences in classrooms taught by these two types of teachers?

\section{Methodology}

\subsection{Participants}

In order to keep the whole process consecutive and comparative, 145 Thai freshmen from 4 different faculties (Liberal Arts, Medicine, Engineering, Management Sciences) at an university in the south of Thailand, who have enrolled in the course of Fundamental English Listening and Speaking during the first semester of the school year 2013, were selected.

Two Thai English lecturers and two English Native-speaker lecturers were chosen on the foundation of their own wills to be observed. All of them teach this same course, Fundamental English listening and speaking. Teacher 1 is a female Thai English teacher who has taught English for 10 years in a southern Thailand University. She used to teach some fundamental English courses for first year university students from different faculties. Teacher 2 is also a female Thai English teacher, with 11 years' teaching experience, including 2 or 3 years at some institute in Nakhon Si Thammarat and 9 years at this University. The groups she taught were also the first year students who studied fundamental English courses, but more often on fundamental Reading and Writing. Teacher 3 and 4 are two native English speakers. Teacher 3 comes from Canada; he started his teaching job here several months ago. Thus, he didn't seem to have much experience in teaching English. So is the situation for Teacher 4, who is from England. However, from the observation of his class, Teacher 4 has a lot of skills of dealing with students.

The course selected for observation is named Fundamental English Listening and Speaking. The reason for choosing this course is that teachers and students tend to have a lot interactions and communications in this class, which is supported by Spada and Frohlich (1995), namely the students and teacher tended to interact with each other most of the time in oral activities. And these characteristics were just demonstrated in this current study during 
the observation process.

\subsection{Instruments}

\subsubsection{Classroom Observation (video-recording)}

Primary researches used to make audio-record to collect data for observing the classroom consequence, which may not be so accurate for the current situation. Since what the audio-records provide are the simulative sound of the lecturers, sometimes the researchers may find it hard to catch the exact words owing to their not being personally on the scene. To resolve this problem and to make the data collected more precise, this current study used video-record, which may better offer the overall perspective of the classroom teaching-learning procedures. Meanwhile, video-record can also give researchers the chance to observe and realize the actual process of learners' language acquisition, especially students' reactions and performance and teachers' perception of the error treatment sequence in classroom. Totally, 16 lessons including 738 minutes' or 12.3 hours' classroom interactions were observed and recorded.

\subsubsection{Interview}

Since classroom observation is the crucial element for this current study, interview is also complementary to the research questions. To better understand teachers' perception of providing feedback, such as their preferred methods, own characters and teaching experience, a follow-up interview was conducted for each teacher after classroom recordings in the present study. Interviews with teacher were in English and each lasted around 30 minutes. The data analysis was based on the interview questions, interview notes and audio-record.

\subsection{Coding and Quantifying}

\subsubsection{Error}

In order to study teachers' diverse strategies to students' performance, students' utterances were coded as turns with error or not. Utterances that contained a simple confirmation, such as yes or no, or that didn't have the potential of containing errors, were excluded. However, this current study didn't exclude the short utterances, like students' acknowledgement or hesitation, inside the error treatment sequences. Based on Lyster and Ranta's (1997) study, this current study coded ill-formed students' utterances as lexical error, grammatical error, phonological error and content error. Since this study focused on comparing native and non-native English teachers, students' use of L1 was also coded as an extra error type in case of investigating the comprehensive perspective of classroom interaction process.

\subsubsection{Feedback}

Teacher utterances including different correction strategies were coded into six types of feedback based on their definitions from Lyster and Ranta's (1997) study, namely recast, explicit correction, elicitation, clarification, repetition and metalinguistic feedback, which were also mingled with some new features according to the specific context in this study. For example, clarification here refers to that teachers ask some questions or make a confirmation 
of students' ill turns in the previous utterances, while elicitation means that teachers ask open questions, or using strategies like pausing to elicit or encourage students to find out the correct form by their own efforts. Namely, clarification checks wrong utterances and find the correct form in the past, while elicitation guide students to look forward to find the alternatives.

\subsubsection{Uptake}

Referring to Lyster and Ranta's (1997) study, there are mainly 2 types of learner uptake, namely repair and needs-repair. Repair means that after teachers' error treatment, students tend to reformulate their error utterance with correct form. On the other hand, needs-repair refers to that students' reformulating utterance still include some incorrect or inappropriate parts.

\subsection{Error Treatment Sequence}

Error treatment sequence model devised by Lyster and Ranta (1997) were applied in this current study to collect the data and analyze the results, which was presented in the following figure. This sequence included three essential elements, namely, learner error, teacher feedback, and learner uptake. However, one more variable - teacher types and some changes inside each of these three elements were also presented in Figure 1.

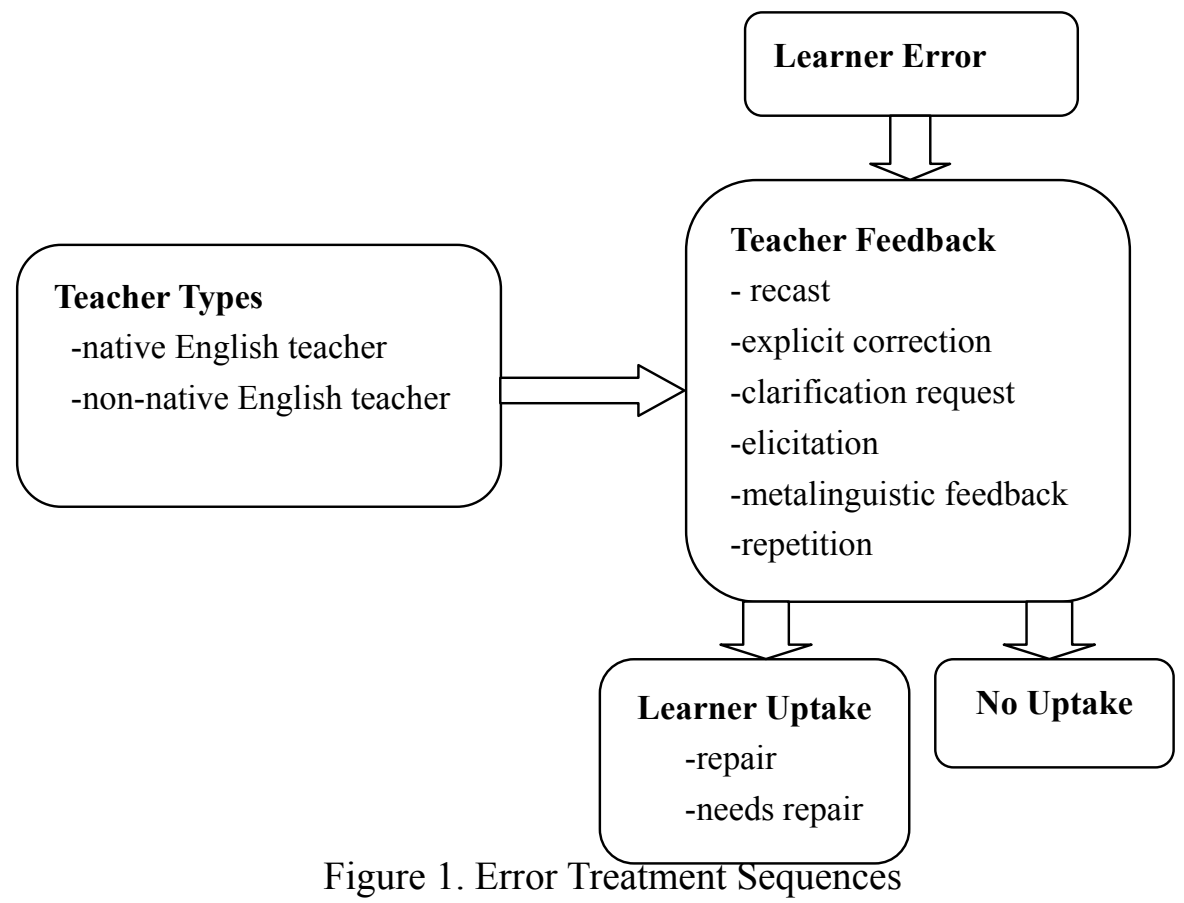

This sequence reflects that during the teaching-learning procedure, students tend to make some errors, which teachers may provide some feedback for students to notice the discrepancy and to make some reformulations. Receiving teachers' feedback, students may either generate the correct form or initiate utterances that still include some mistakes. Since teacher types, both native and non-native English teachers, were believed to be a variable which may influence the error correction process, lecturers' types were also added in the 
sequence to make the comparison among teacher types, teacher feedback, student errors and student uptakes possible.

During observations of 12.3 hours' classroom interactions happened from week 6 to week 10 of the 15-week course, video-record was introduced and students' reaction, including gestures and facial expression, and teacher's perception were recorded. All the records, 3 hours for each class were analyzed to ensure the quantity and quality of teacher-student utterances.

\section{Results and Discussions}

\subsection{Overall Error Treatment Sequences in Four Classrooms.}

Since error-comment-repair is the common and basic error correction process happening in almost every classroom, this current study, based on Lyster and Ranta's (1997) analytic model, focused on examining the error treatment sequences occurred in four classrooms with the fundamental factors such as student errors, teacher feedback and student uptake.

Table 1. Basic Error Treatment Sequence in Four Classrooms

\begin{tabular}{|c|c|c|}
\hline Student Errors & Teacher Feedback & Student Responses \\
\hline \multirow{3}{*}{399} & \multirow{3}{*}{399} & Repair 137 (34\%) \\
\hline & & Needs Repair 107 (27\%) \\
\hline & & No Uptake 155 (39\%) \\
\hline
\end{tabular}

As can be seen in Table 1, the basic error treatment sequence showed three ways of interactions occurred in all the four classrooms. Since this research aimed to study the error correction sequences, student errors which led to no teacher feedback were excluded to guarantee the results. Thus, the total 399 student errors in this Table referred to those which were followed by teacher feedback. The first sequence in Table 1 exhibited that 137 errors that followed by teacher feedback were finally repaired, which accounted for $34 \%$ of all these 399 errors. The second sequence showed that 107 errors followed by teacher feedback led to needs repair, which on the other hand meant that $27 \%$ of these errors being corrected still included something inappropriate. While, the last basic sequence was that $39 \%$ of errors followed by teacher feedback received no response from students. All these results indicate that student errors treated by teacher feedback could lead to students' responses, including repair, needs repair and no uptake, at quite even distribution in the current study.

In order to discover more details about all the sequences occurred in four classrooms and to explore the relatively more effective sequence in all classes, more detailed sequences were presented in the following Tables.

The sequence in Table 2 basically demonstrated that the errors followed by recast usually led to three subsequent results: $21 \%$ corrected, $10 \%$ needs repair and $69 \%$ no response. Thus, even though recast was the most frequently used feedback given to resolve 195 errors out of 
the total 399 errors, the effectiveness of this sequence tended to be low, with nearly $70 \%$ of the errors resulting in no student uptake.

Table 2. First Error Treatment Sequence in all Four Classrooms

\begin{tabular}{ll|l}
\hline \multirow{2}{*}{ Student Errors } & Recast & \multicolumn{1}{l}{ Student Responses } \\
\hline \multirow{3}{*}{195} & \multirow{3}{*}{195} & Repair 42 $(21 \%)$ \\
& & Needs Repair 19 $(10 \%)$ \\
\cline { 2 - 2 } & No Uptake 134 (69\%)
\end{tabular}

All these may suggest that although recast was provided to most of the errors, the error treatment sequence including recast tended to be less successful in leading to students' repairs. Even the $21 \%$ errors being corrected were not student-generated repair, but merely students' repetition to teachers' correct reformulations. Thus, to keep the effectiveness of error correction process in future pedagogical activities, lecturers or teachers are recommended to avoid producing error treatment sequence including recast.

Table 3. Second Error Treatment Sequences in Four Classrooms

\begin{tabular}{|c|c|c|}
\hline Student Errors & Explicit Correction & Student Responses \\
\hline \multirow{3}{*}{30} & \multirow{3}{*}{30} & Repair $12(40 \%)$ \\
\hline & & Needs Repair $0(0 \%)$ \\
\hline & & No Uptake $18(60 \%)$ \\
\hline
\end{tabular}

The sequence in Table 3 was quite similar to the sequence in Table 2 though the exact error numbers were not. As can be seen, $40 \%$ of student errors (12 errors) treated by teachers' explicit correction finally led to repair, which was also students' rephrasing of teachers' correct comments. At the same time, $60 \%$ of student errors (18 errors) followed by explicit correction led to no student uptake. Thus, the sequence consisting of explicit correction tended to be less effective in correcting student mistakes too, hence, not recommended to be used. Looking at the definitions and examples of explicit correction and recast, some similar features among these two types of teacher feedback can be seen as that both provide correct forms for students to follow and repeat. In other words, they were usually the teachers' reformulations of students' ill-formed utterances, instead of triggering the interactions between lecturer and learners. Thus, the corrections were usually the students' repetition or cooperation with teachers' correct modification. Therefore, for pedagogical instructions, teachers are recommended to produce error treatment sequence without recast or explicit correction, feedback types which cannot initiate the negotiation between teachers and 
students.

Table 4. Third Error Treatment Sequence in Four Classrooms

\begin{tabular}{|c|c|c|}
\hline Student Errors & Elicitation & Student Responses \\
\hline \multirow{3}{*}{75} & \multirow{3}{*}{75} & Repair 44 (59\%) \\
\hline & & Needs Repair $31(41 \%)$ \\
\hline & & No Uptake $0(0 \%)$ \\
\hline
\end{tabular}

Table 4 exhibited the basic error treatment sequence that included teachers' elicitation, which seemed to be more effective in resulting to students self-repair, since almost $60 \%$ of student errors treated by elicitation resulted in student repairs. The repairs followed by elicitation were usually student-generated correction, which was testified by both previous studies (Lyster \& Ranta, 1997) and the current study. However, there were still $41 \%$ of students errors dealt with elicitation finally resulting in needs repair as the second sequence. The results showed that all the errors treated by elicitation led to student-generated responses, either repair or needs repair and none of them ended with no uptake. Thus, this sequence seemed to be the successful one which can result in high rate of students' repairs. As a result, it should be employed often in the teaching process.

Table 5. Fourth Error Treatment Sequence in Four Classrooms

\begin{tabular}{|c|c|c|}
\hline Student Errors & Clarification & Student Responses \\
\hline \multirow{3}{*}{77} & \multirow{3}{*}{77} & Repair $32(42 \%)$ \\
\hline & & Needs Repair 43 (56\%) \\
\hline & & No Uptake $2(2 \%)$ \\
\hline
\end{tabular}

Table 6. Fifth Error Treatment Sequence in Four Classrooms

\begin{tabular}{|c|c|c|}
\hline Student Errors & Repetition & Student Responses \\
\hline \multirow{3}{*}{16} & \multirow{3}{*}{16} & Repair $6(38 \%)$ \\
\hline & & Needs Repair $10(62 \%)$ \\
\hline & & No Uptake $0(0 \%)$ \\
\hline
\end{tabular}


The sequences in Table 5 and 6 which included clarification and repetition also shared some similarities with the sequences shown in Table 4. Quite a number of student errors -- 98\% of all the errors followed by clarification and $100 \%$ of errors dealt with repetition led to students' responses. Only $2 \%$ and $0 \%$ of them respectively resulted in no uptake. The relatively effective sequence in Table 5 was that $42 \%$ of the errors followed by clarification were corrected by students, while $56 \%$ of them eventually generated needs repair. Meanwhile, in Table $6,38 \%$ of the errors receiving repetition resulted in students repairs, which was also relatively effective. Still, $62 \%$ of the errors followed by repetition led to needs repair. Apparently, however, repetition was used much less frequently (16 times) than clarification (77 times). Thus, instead of simply using elicitation to stimulate successful error treatment sequence, teachers may opt for clarification and repetition to ensure effective error corrections.

Table 7. Sixth Error Treatment Sequence in Four Classrooms

\begin{tabular}{|c|c|c|}
\hline Student Errors & Metalinguistic Feedback & Student Responses \\
\hline \multirow{3}{*}{6} & \multirow{3}{*}{6} & Repair $1(17 \%)$ \\
\hline & & Needs Repair $4(66 \%)$ \\
\hline & & No Uptake $1(17 \%)$ \\
\hline
\end{tabular}

The last sequence occurred in all four classroom was the one which included metalinguistic feedback, as shown in Table 7. Only 6 students errors were followed by teachers' metalinguistic feedback, with 1 of them being repaired, 4 of them resulting in needs repair and 1 of them led to no student response. This result may indicate that the sequence with metalinguistic feedback was the least occurred error treatment sequence triggered by all the teachers in this study.

Overall, error treatment sequences including elicitation, clarification and repetition which can generate negotiation between teacher and students, seemed to be more successful in correcting student errors, and the repairs inside these sequences were always student-generated. Meanwhile, the error correction sequences which consisted of recast, explicit correction and metalinguistic feedback were demonstrated to be less effective in leading to student uptake in the current study.

\subsection{Similarities and Differences of the Error Treatment Sequences inside both Native and} Non-Native English Teachers' Classes

The following two Tables (Table 8 and Table 9) exhibited the error treatment sequences happening inside both Native English Speaker teachers and Non-Native English Speaker teachers' classes. Since this study focused on six main feedback types used by both types of teachers, there were six basic error treatment sequences followed by these six types of teacher feedback. 
Table 8 and Table 9 show that Non-Native English teachers provided feedback to 288 student errors, while Native English teachers only gave feedback to 111 student mistakes. However, student errors treated by Native teachers' feedback seemed to result in a bit more successful student repairs, with the rate of $40 \%$ in Native teachers' class compared with $33 \%$ in Non-Native teachers' class. Meanwhile, $26 \%$ of student errors followed by Non-Native teachers' feedback finally turned into needs repair and $41 \%$ of the errors led to no student response in Non-Native teachers' classes. On the other hand, in Native teachers' classes, 28\% students' mistakes treated by teacher feedback resulted in needs repair, while $32 \%$ of them finally received no response from students.

Table 8. Error Treatment Sequences inside Non-Native Teachers' Classes

\begin{tabular}{|c|c|c|c|c|}
\hline \multirow{2}{*}{ Student Error } & \multirow{2}{*}{ Teacher Feedback } & \multicolumn{3}{|c|}{ Student Uptake } \\
\cline { 3 - 5 } & & Repair & Needs Repair & No Uptake \\
\hline 150 & Recast $(\mathrm{n}=150)$ & $28(19 \%)$ & $15(10 \%)$ & $107(71 \%)$ \\
\hline 19 & Explicit Correction $(\mathrm{n}=19)$ & $10(53 \%)$ & $0(0 \%)$ & $9(47 \%)$ \\
\hline 52 & Elicitation $(\mathrm{n}=52)$ & $30(58 \%)$ & $22(42 \%)$ & $0(0 \%)$ \\
\hline 54 & Clarification $(\mathrm{n}=54)$ & $21(39 \%)$ & $31(57 \%)$ & $2(4 \%)$ \\
\hline 10 & Repetition $(\mathrm{n}=10)$ & $4(40 \%)$ & $6(60 \%)$ & $0(0 \%)$ \\
\hline 3 & Metalinguistic $(\mathrm{n}=3)$ & $0(0 \%)$ & $2(67 \%)$ & $1(33 \%)$ \\
\hline Total $(\mathrm{n}=288)$ & Total $(\mathrm{n}=288)$ & $93(33 \%)$ & $76(26 \%)$ & $119(41 \%)$ \\
\hline
\end{tabular}

Table 9. Error Treatment Sequences inside Native Teachers' Classes

\begin{tabular}{|c|c|c|c|c|}
\hline \multirow{2}{*}{ Student Error } & \multirow{2}{*}{ Teacher Feedback } & \multicolumn{3}{|c|}{ Student Uptake } \\
\cline { 3 - 5 } & & Repair & Needs Repair & No Uptake \\
\hline 45 & Recast $(\mathrm{n}=45)$ & $14(31 \%)$ & $4(9 \%)$ & $27(60 \%)$ \\
\hline 11 & Explicit Correction $(\mathrm{n}=11)$ & $2(18 \%)$ & $0(0 \%)$ & $9(82 \%)$ \\
\hline 23 & Elicitation $(\mathrm{n}=23)$ & $14(61 \%)$ & $9(39 \%)$ & $0(0 \%)$ \\
\hline 23 & Clarification $(\mathrm{n}=23)$ & $11(48 \%)$ & $12(52 \%)$ & $0(0 \%)$ \\
\hline 6 & Repetition $(\mathrm{n}=6)$ & $2(33 \%)$ & $4(67 \%)$ & $0(0 \%)$ \\
\hline 3 & Metalinguistic $(\mathrm{n}=3)$ & $1(33 \%)$ & $2(67 \%)$ & $0(0 \%)$ \\
\hline Total $(\mathrm{n}=111)$ & Total $(\mathrm{n}=111)$ & $44(40 \%)$ & $31(28 \%)$ & $36(32 \%)$ \\
\hline
\end{tabular}

Even though Non-Native English teachers seemed to provide more recast, error treatment 
sequence including teachers' using of recast in both Native and Non-Native teachers' classes, tended to have some similar features. For example, students mistakes dealt with by teachers' recast in both two types of classes resulted in a high rate of no student response, $71 \%$ in Non-Native teachers' classes and $60 \%$ in Native teachers' classes. Meanwhile, the rate of student repair in both classrooms were $19 \%$ and $31 \%$, and the rate of student needs repair in these two classrooms were $10 \%$ and $9 \%$ respectively. All these may indicate that error treatment sequences including recast produced by either Native or Non-Native teachers, seemed to be ineffective in leading to students' responses.

However, the second error treatment sequence which included explicit correction tended to be quite different when used by Native and Non-native teachers. The error treatment sequence in Non-native English teachers' class tended to be more effective in leading to student repairs. For example, $53 \%$ of the student mistakes treated by explicit correction in Non-Native teachers' class resulted in student repair, and $47 \%$ of them led to no response. Nevertheless, in Native teachers' classes, $82 \%$ of student errors dealt with explicit correction finally received no uptake from students. Only $18 \%$ of student errors were eventually corrected following explicit correction. This may illustrate that error treatment sequence produced by different types of teachers could also lead to diverse levels of effectiveness.

The third sequence in both Native and Non-Native teachers' classes were proved to be the most effective error treatment sequence that led to high rate of students' repairs, $61 \%$ and $58 \%$ respectively. Only $42 \%$ of student errors in Non-Native teachers' class and $39 \%$ of student errors in Native teachers' class turned into needs repair. All students' errors in both classrooms receiving elicitation led to student responses; either repair or needs repair. The following 3 error treatment sequences in both types of classrooms also shared some similarities. Student errors followed by clarification, repetition and metalinguistic feedback seldom led to no student uptake, and most student mistakes dealt by these three types of feedback resulted in needs repair. All these may suggest that error treatment sequences containing elicitation, clarification and repetition seem to be effective of resulting in students' responses no matter who uses them. Teachers or researchers in their future practices may take these results into consideration and make some arrangements to apply these findings in actual and specific situations.

\section{Discussion and Conclusion}

Based on the consecutive studies conducted by Lyster and Ranta (1997), Lyster (2001) and Panova and Lyster (2002) which unveiled the error treatment sequence in classroom and an analytic model, the current study made some similar investigation on teacher and students' interaction process, especially the error treatment sequences occurred in both Native and Non-Native English teachers' classrooms. The settings of this study were unique in the following aspects: a) a new variable, namely teacher types (native and non-native English teachers) was introduced in this study; b) exploration on the relationship between teacher types and error treatment sequences; c) the students being studied came from southern Thailand, which could to some extent be a representative of Asian students. Despite these differences, Lyster and Ranta's (1997) analytic model was applied in this study and proved to 
be applicable and effective. Error treatment sequences happened in different classroom environments were especially investigated in this study to show the effects of this new variable, namely teacher types (native and non-native English teachers) on the error correction process.

Totally, in all four classrooms, error treatment sequences, leading to student repair, needs repair or no uptake, seemed to distribute at similar proportion. Error treatment sequence which included recast seemed to be the most common sequence generated by all the four teachers. However, most of student mistakes treated by recast resulted in no uptake and the repairs after recast were simply students' repetition of teachers' correct addresses. This may suggest that this error treatment sequence tends to be less effective in inducing the correction of students' errors. This was also true with the error treatment sequences that consisted of explicit correction. Thus, in future pedagogical activities, teachers should avoid producing the error treatment sequences including recast and explicit correction to ensure the effectiveness of mistake correction process. On the other hand, the error treatment sequences which contained elicitation, clarification and repetition, tended to generate high rate of students' repairs, and these repairs were usually student self-initiated. Even though the frequency of elicitation was not the highest, the error treatment sequence carried on by elicitation tended to be the successful one that effectively alters students' mistakes to student-generated repairs. Thus, teachers may take this finding into consideration and apply this sequence in their own teaching process with some adjustments. Meanwhile, teachers, who favor providing varied effective mistake correction processes, may select clarification and repetition to stimulate successful error treatment sequences. Nonetheless, the sequence including metalinguistic feedback was the least generated error treatment sequence which also led to low rate of students' repairs in this study, thus would not be recommended for effective teaching. All these may suggest that teachers should avoid the error treatment sequences which results in high rate of no student uptake, and try to initiate more error treatment sequences which can be effective in leading to student-generated repairs. Since this study focused on the first year university students, teachers in future pedagogical practices should also take their students' proficiency level into consideration when generating the error treatment sequences.

Furthermore, there were both similarities and differences in terms of the error treatment sequences in Native and Non-Native English teachers' classes. For example, the error treatment sequence including recast in both classes tended to lead to high rate of no response from students. This result may implicate that no matter generated by what types of teachers, error treatment sequences with recast, seemed to be ineffective in leading to students' responses, especially the repair. Thus, teachers in the real teaching practices had better choose alternative strategies that can stimulate effective error treatment sequence. Those sequences with elicitation seemed to be the most effective process that resulted in high rate of students' repairs and should be recommended for further teaching or researching. Meanwhile, seldom error treatment sequences inside both Native and Non-Native teachers' classes, which consisted of clarification, repetition and metalinguistic feedback, resulted in no student response, which suggests that these sequences seemed to trigger high rate of students' responses, both repair and needs repair. Therefore, teachers may opt for these feedback 
strategies to stimulate varied effective error treatment sequences. However, those sequences which comprise explicit correction led to different results in Native and Non-Native teachers' classes; the sequences in Non-Native Teachers' class seemed more successful in leading to students' repair than in Native Teachers' class. Thus, this result may indicate that same error treatment sequence produced by different types of teachers could be different in the effectiveness of leading to students' repairs. However, due to the low frequency of this sequence including explicit correction and the small scale of research, future studies may apply and examine this result in other situations considering their own features.

All these results might indicate that no matter what types of teacher they are, the error treatment sequences including recast and explicit correction tend to be less effective than those with elicitation, clarification, repetition and metalinguistic feedback, in leading to students' repairs; teachers, whether Native or Non-native, should generate error treatment sequences, which includes elicitation or clarification instead of recast, in order to make the teaching and learning process more effective; lecturers or researchers should also take their own situation and the limitation of current study into consideration when applying these findings in the real teaching process or experiments. Since this study was conducted only in one university in southern Thailand and the target group were quite small (only four classes), large scale of investigations, concerning more variables such as teachers' teaching approaches, background knowledge and students' proficiency levels are needed to generalize the findings in this study. Future studies which are interested in the error treatment sequence, may also take more feedback strategies into consideration or make different classifications about feedback types such as explicit feedback and implicit feedback, oral feedback and writing feedback to examine and expand the results of this current study.

\section{Acknowledgement}

This research was supported by Prince of Songkla University, Hatyai campus, Thailand. Great thanks for Professor Monta, Chonlada and Jomjai for their kind help and instructions. Thanks for the active participation of the 4 English teachers and their students. Meanwhile, gratefully thanks to the staffs in Faculty of Liberal Arts for their patient assistances and contributions to various phrases of this research.

\section{References}

Adams, R., Nuevo, A. M., \& Egi, T. (2011). Explicit and Implicit Feedback, Modified Output, and SLA: Does Explicit and Implicit Feedback Promote Learning and Learner-Learner Interactions. The Modern Language Journal, 95, 42-63. http://dx.doi.org/10.1111/j.1540-4781.2011.01242.x

Árva, V., \& Medgyes, P. (2000). Native and non-native teachers in the classroom. System, 28, 355-372. http://dx.doi.org/10.1016/S0346-251X(00)00017-8

Chaudron, C. (1977). A descriptive model of discourse in the corrective treatment of learners' errors. Language Learning, 27, 29-46.

Chaudron, C. (1986). Teachers' priorities in correcting learners' errors in French immersion 
classes. In R. Day (Ed.), Talking to learn (pp. 64-84). Rowley, MA: Newbury House.

Chaudron, C. (1988). Second language classrooms. New York: Cambridge University Press. http://dx.doi.org/10.1017/CBO9781139524469

Clark, E., \& Paran, A. (2007). The employability of non-native-speaker teachers of EFL: A UK survey. System, 35 (4), 407-430. http://dx.doi.org/10.1016/j.system.2007.05.002

Doughty, C. (1994a). Finetuning of feedback by competent speakers to language learners. In J. Alatis (Ed.), GURT 1993 (pp. 96-108). Washington, DC: Georgetown University Press.

Gibbons, P. (2003). Mediating Language Learning: Teacher Interactions with ESL Students in a content based classroom. TESOL Quarterly, 37 (2), 247-274. http://dx.doi.org/10.2307/3588504

Hendrickson, J. M. (1978). Error correction in foreign language teaching: Recent theory, research, and practice. The Modern Language Journal, 62, 387-398. http://dx.doi.org/10.1111/j.1540-4781.1978.tb02409.x

Li, S. (2010). The Effectiveness of Corrective Feedback in SLA: A Meta-Analysis. Language Learning, 60, 309-365. http://dx.doi.org/10.1111/j.1467-9922.2010.00561.x

Long, M. H. (1996). "The role of the linguistic environment in second language acquisition". In Ritchie, William; Bhatia, Tej. Handbook of second language acquisition. San Diego: Academic Press. 413-468. http://dx.doi.org/10.1016/B978-012589042-7/50015-3

Lyster, R., \& Ranta, L. (1997). Corrective feedback and learner uptake. Studies in Second Language Acquisition, 19, 37-61. http://dx.doi.org/10.1017/S0272263197001034

Lyster, R. (2001). Negotiation of form, recasts, and explicit correction in relation to error types and learner repair in immersion classrooms. Language Learning, 51, 265-301. http://dx.doi.org/10.1111/j.1467-1770.2001.tb00019.x

Medgyes, P. (1994). The Non-Native Teacher. London: Macmillan.

Noemi, R. D. (2009). A Comparative study of native and non-native teachers' scaffolding techniques in SLA at an early age. Estudios Ingleses de la Universidad Complutense, vol. 17, $57-73$.

Panova, I., \& Lyster, R. (2002). Patterns of Corrective Feedback and Uptake in an Adult ESL Classroom. TESOL Quarterly, 36 (4), 573-595. http://dx.doi.org/10.2307/3588241

Richards, C. J., John P., \& Heidi, P. (2000). Longman Dictionary of Language Teaching \& Applied Linguistics. Beijing, China: Foreign Language Teaching and Research Press.

Slimani, A. (1992). Evaluation of classroom interaction. In C. Anderson \& A. Beretta (Eds.), Evaluating second language education (pp. 197-221). Cambridge: Cambridge University Press. http://dx.doi.org/10.1017/CBO9781139524575.009

Spada, N., \& Frohlich, M. (1995). COLT. Communicative Orientation of Language Teaching observation scheme: Coding conventions and applications. Sydney, Australia: National 


$\underline{M}$ Macrothink

Centre for English Language Teaching and Research.

Suzuki, M. (2004). Corrective Feedback and Learner Uptake in Adult ESL Classrooms. Teachers College, Columbia University Working Papers in TESOL \& Applied Linguistics, Vol. 4, No. 2.

Swain, M. (1985). Communicative competence: Some roles of comprehensible input and comprehensible output in its development. In S. Gass \& C. Madden (Eds.), Input in second language acquisition. (pp. 235-253). Rowley, MA: Newbury House.

Yoshida, R. (2010). How Do Teachers and Learners Perceive Corrective Feedback in the Japanese Language Classroom? The Modern Language Journal, 94, 293-314. http://dx.doi.org/10.1111/j.1540-4781.2010.01022.x

\section{Copyright Disclaimer}

Copyright reserved by the author(s).

This article is an open-access article distributed under the terms and conditions of the Creative Commons Attribution license (http://creativecommons.org/licenses/by/3.0/). 